\title{
Progress in Rectal Cancer Treatment
}

\author{
Wim P. Ceelen \\ Department of Surgery, Ghent University Hospital, De Pintelaan 185, 9000 Ghent, Belgium
}

Correspondence should be addressed to Wim P. Ceelen, wim.ceelen@ugent.be

Received 24 June 2012; Accepted 8 August 2012

Academic Editors: O. El Sibai and H. Kuwano

Copyright ( 2012 Wim P. Ceelen. This is an open access article distributed under the Creative Commons Attribution License, which permits unrestricted use, distribution, and reproduction in any medium, provided the original work is properly cited.

\begin{abstract}
The dramatic improvement in local control of rectal cancer observed during the last decades is to be attributed to attention to surgical technique and to the introduction of neoadjuvant therapy regimens. Nevertheless, systemic relapse remains frequent and is currently insufficiently addressed. Intensification of neoadjuvant therapy by incorporating chemotherapy with or without targeted agents before the start of (chemo)radiation or during the waiting period to surgery may present an opportunity to improve overall survival. An increasing number of patients can nowadays undergo sphincter preserving surgery. In selected patients, local excision or even a "wait and see" approach may be feasible following active neoadjuvant therapy. Molecular and genetic biomarkers as well as innovative imaging techniques may in the future allow better selection of patients for this treatment option. Controversy persists concerning the selection of patients for adjuvant chemotherapy and/or targeted therapy after neoadjuvant regimens. The currently available evidence suggests that in complete pathological responders long-term outcome is excellent and adjuvant therapy may be omitted. The results of ongoing trials will help to establish the ideal tailored approach in resectable rectal cancer.
\end{abstract}

\section{Introduction}

Significant advancements have been made during the last decades in the treatment of rectal cancer. Once considered an incurable disease, treatment-related morbidity and mortality have decreased from $100 \%$ to less than $5 \%$ [1]. At the same time, the risk of locally recurrent disease, once seen in over $30 \%$ of patients and associated with a horrible fate, has been reduced to less than $5 \%$ in recent years. The progress in oncological outcome has led to the observation that, very recently, the long-term survival of rectal cancer is actually better than that of colon cancer [2]. This progress may be attributed to increased attention to surgical technique and to the introduction of combined modality therapy regimens. Nevertheless, several uncertainties persist regarding neoadjuvant therapy approaches, extent and technique of surgery, and selection for adjuvant therapy. Here, we highlight the currently accepted standard of care in the several steps of the patient's treatment trajectory. Also, we identify areas of uncertainty or controversy and identify important ongoing clinical studies aiming to resolve these issues.

\section{Staging}

The aim of staging procedures is twofold: first, to enable to tailor the therapeutic approach to the extent of locoregional as well as systemic disease identified and, second, to allow prognostic stage grouping and identification of those patients at high risk of recurrence.

General staging includes measurement of carcinoembryonic antigen (CEA) and CT scan of chest and abdomen. Compared to colon cancer, the incidence of synchronous and metachronous pulmonary metastasis is notably higher in rectal cancer patients, a finding likely explained by the fact that venous drainage of the mid and lower rectum is systemic rather than portal [3-6].

Locoregional staging essentially comprises endoscopic ultrasound (EUS) and magnetic resonance imaging (MRI). Endoscopic ultrasound is readily available, inexpensive, and allows accurate staging of early cancers. The sensitivity and specificity of EUS in stage $\mathrm{T} 1$ and $\mathrm{T} 2$ tumours are $>90 \%$ and $>85 \%$, respectively, while the accuracy of EUS to predict mesorectal nodal involvement is $70 \%-80 \%$ [7-9]. The disadvantages of EUS include its invasive nature and 
the inability to assess the circumferential resection margin (CRM).

Thin-section, T2-weighted, phased-array coil MRI of the pelvis allows excellent soft tissue spatial and contrast resolution. The MERCURY (Magnetic Resonance Imaging and Rectal Cancer European Equivalence) multicenter study group examined the ability of MRI to predict extramural invasion depth (EMD) by comparing imaging data with histopathological analysis of the resected specimens [10]. They found that, in an analysis of 295 patients, the mean difference between the MRI derived and histopathologically derived EMD was only $-0.05 \mathrm{~mm}$ ( $95 \%$ confidence interval $-0.49-0.40$ ), resulting in actual equivalence between MRI and histological assessment of tumour spread. Similarly, the same group showed that MRI is highly accurate in predicting tumour involvement of the CRM and, thus, the likelihood of obtaining an R0 resection when primary surgery is used [11].

Mesorectal nodal metastasis represents one of the most powerful prognosticators in rectal cancer. Iconographic detection of nodal positivity is hampered by the considerable overlap in size between normal and cancer-invaded lymph nodes. When size criteria are combined with other morphological features such as mixed intranodal signal or border irregularity, the accuracy of MRI in predicting nodal status may reach $85 \%$ [12]. Accuracy may be further improved by using lymphotropic contrast agents such as ultrasmall superparamagnetic particles of iron oxide (USPIO), which are taken up by normal but not by tumour-invaded lymph nodes. Several authors have succeeded in considerably improving MRI accuracy of nodal staging with the USPIO ferumoxtran-10 [13-15]. Lambregts et al. reported the use of the macromolecular contrast agent gadofosveset (MS325), which is reversibly bound to plasma albumin [16]. They found that, using histolopathology as the standard reference, sensitivity and specificity of nodal staging improved from $76 \%$ and $82 \%$ to $80 \%$ and $97 \%$, respectively, compared to standard MRI $(P<0.001)$.

\section{Surgery}

There is no doubt that the dramatic improvements in local control of rectal cancer during the past three decades are first and foremost due to improvements in surgical training and attention to technique [17-20]. The basic principles of total mesorectal excision (TME) are twofold: first, sharp dissection between the visceral and parietal layers of the mesorectal fascia and, second, complete excision of the mesorectum down to the pelvic floor in mid and low lying rectal cancer. The latter principle is based on the seminal observations by Heald and Quirke, who noted that the mesorectum may harbor tumour deposits up to $4 \mathrm{~cm}$ distal (caudal) to the lower edge of the luminal tumour [21-24]. In parallel, it was realized that the distal bowel resection margin may be safely reduced to less than $10 \mathrm{~mm}$, and this finding, combined with novel strategies such as intersphincteric resection and coloanal anastomosis, has led to a significant increase in sphincter preserving procedures [25-29]. In patients with low lying tumours necessitating rectal amputation, the improvements in local control have been far less satisfying. This may be explained by an inherently different (namely, more invasive) tumour biology, but surgical factors were shown to play an important part. Indeed, when the mesorectal plane is dissected down to the pelvic floor, one inevitably gets very close to the tumour when it is located near the dentate line, a location where the mesorectum becomes very thin. Investigators from the Dutch Rectal Cancer Trial demonstrated that, compared to anterior resection, abdominoperineal resection resulted in a significantly higher risk of involved CRM (26.5\% versus $12.6 \%, P<0.001$ ), a higher rate of tumour perforation, and worse survival [29]. The recent introduction of "cylindrical" resection, encompassing wide or complete removal of the levator muscle plate en bloc with the rectal amputation specimen, was shown to reduce the risk of CRM involvement, intraoperative perforation, and local recurrence [3032]. In colon cancer, randomized trials have shown that, compared to open surgery, laparoscopic- or laparoscopyassisted approaches are associated with significant functional advantages while cancer recurrence rates are similar [33, 34]. In rectal cancer, where preservation of the intact mesorectal envelope is of critical importance, the feasibility and safety of laparoscopic resection were suggested in several small trials [35]. The oncological equivalence of laparoscopic versus open rectal cancer surgery will need to be demonstrated by the ongoing prospective randomized trials: COLOR II, Japanese JCOG 0404, and ACOSOG Z6051 [36-38]. Preliminary results from the COLOR II trials were recently reported [39]. A total of 1103 patients were randomized to either laparoscopic or open rectal cancer surgery in a $2: 1$ ratio. No differences were observed in circumferential or distal margin, anastomotic leakage rate $(8.8 \%$ versus $10 \%$ after laparoscopic versus open surgery, resp.; $P=0.63$ ), or nodal count. However, the laparoscopic approach resulted in less blood loss, less analgesic use, quicker return of GI function, and shorter hospital stay. Conversion to open surgery was required in $16 \%$ of the patients allocated to laparoscopic surgery. Clearly, when confirmed by long-term oncological equivalence, the laparoscopic approach may be advised in selected patients.

For most patients, avoidance of a permanent colostomy in low lying tumours is a concern. The introduction of longterm neoadjuvant chemoradiation followed by downsizing of the tumour allows to achieve sphincter preservation in many cases. In parallel, the technique of intersphincteric resection, colonic pull through, and manual coloanal anastomosis has gained popularity in low lying cancers. It has been shown that, in contrary to mesorectal distal tumour spread, infiltration of the rectal wall distally from the macroscopic lower tumour border is very uncommon and, consequently, a distal resection margin of $10 \mathrm{~mm}$ does not compromise R0 resection. Bujko and coworkers performed a meta-analysis of 17 studies reporting local recurrence rate according to distal resection margin (less than versus at least $1 \mathrm{~cm}$ ) and found no statistically significant difference in local recurrence rate or overall survival [19]. It is clear, however, that functional results are potentially much worse after coloanal anastomosis and careful preoperative counseling is therefore mandatory, 
specifically in the elderly or those with preexisting impaired continence $[29,40]$.

\section{Neoadjuvant Radiation and Combined Modality Therapy}

Significant advances have been made in local control of advanced rectal cancer by combining surgery with either preor postoperative radiation therapy (RT). A meta-analysis based on individual patient data (IPD) published in 2001 showed that preoperative RT reduced the yearly risk of local recurrence with $46 \%(P=0.00001)$, while postoperative RT reduced the risk with $37 \%(P=0.002)$ [41]. Overall survival, however, was only marginally improved $(62 \%$ versus $63 \%$; $P=0.06)$. From a theoretical point of view, preoperative $\mathrm{RT}$ is associated with several advantages compared to the postoperative approach. First, RT will be more active in surgically undisturbed, well-oxygenized tissue. Second, only the preoperative approach may result in downstaging and downsizing effects. Third, postoperative RT administration may be hampered by compliance issues in the postoperative setting and may lead to increased radiation damage to the small bowel. Superiority of preoperative to postoperative chemoradiation was demonstrated by the German rectal cancer trial, showing that the preoperative approach resulted in improved local control and less toxicity, but no difference in overall survival was noted [42].

Importantly, it has been shown that protracting RT duration shifts the dose-response curve that describes control of subclinical pelvic tumour deposits to the right, resulting in a higher dose required to exert a similar reduction in pelvic relapse rate [43]. A recent meta-analysis and metaregression related the biologically equivalent dose (BED) and fractionation schedule of preoperative RT to survival, local control, and sphincter preservation rate in rectal cancer [44]. It was found that, when a BED of more than 30 Gray is used, both short-term and long-term RT schedules were effective in improving local control and survival, while only a longterm schedule resulted in increased sphincter preservation. The Dutch randomized rectal cancer trial showed that preoperative short-term RT is effective even when standardized, quality-controlled TME surgery is routinely used [45]. The recently published 12-year update from this trial confirmed a significant reduction in local recurrence rate $(5 \%$ after RT followed by surgery versus $11 \%$ in the surgery alone group, $P<0.0001$ ) [46]. Of note, the results of this trial also showed that, in patients with involved resection margins, preoperative RT cannot prevent local recurrence [47].

There are sound theoretical arguments for combining RT with chemotherapy. First, several chemotherapeutic agents act as radiosensitizers and will enhance the pathological effects of RT. Second, early incorporation of chemotherapy might address concurrent systemic disease. Several prospective randomized trials have compared preoperative RT alone with preoperative chemoradiation (CRT) in locally advanced rectal cancer (Table 1). The results of the completed trials and ongoing studies with preliminary results may be summarized as follows: compared to RT alone, preoperative
CRT improves pathological response and local control but is associated with more pronounced treatment-related toxicity. In addition, CRT does not benefit sphincter preservation rate or long-term survival rate [48]. Debate persists regarding the place of short course RT (SCRT) schedules (usually $5 \times 5$ Gray) followed by immediate surgery. Arguments in favour include (1) the fact that SCRT has been tested and found to be effective in multiple randomized trials, (2) convenience for the patient, and (3) the similarity in long-term outcome when compared with long-term (C)RT schedules. Disadvantages of SCRT include significant early and delayed toxicity (including secondary malignancies) observed in the Swedish and Dutch rectal cancer trials, and the inability to achieve downstaging and downsizing when immediate surgery (within 5-10 days) is performed [49-52]. It should be noted, however, that with modern conformal RT delivery techniques the differences in toxicity between SCRT and long schedule RT schedules seem minimal. An important question is whether a longer waiting period after SCRT would achieve pathological downstaging to the extent observed with long-term schedules. The interim results from the trial reported by Latkauskas et al., who randomized patients to receive either SCRT or CRT and included a six weeks waiting period in both groups, demonstrated a far superior pathological response in the group who underwent chemoradiation [53]. Additional answers are awaited in this regard from the ongoing Stockholm III trial, which randomizes patients to receive either SCRT with immediate surgery, SCRT with delayed (after 4-8 weeks) surgery, or long course radiotherapy $(25 \times 2$ Gray $)$ with delayed surgery [54].

Incorporation of additional chemotherapy agents in preoperative regimens, aiming at further enhancing pathological response whilst possibly improving overall survival, seemed a rational step. Several phase III trials have been initiated incorporating oxaliplatin, an agent which is active in the adjuvant and palliative setting, in CRT regimens. From four of these trials, interim data are available (Table 2). The first results of the PETACC- 6 trial, which randomizes patients to preoperative RT (50.4 Gray in 25 fractions) with capecitabine alone or with capecitabine + oxaliplatin $\left(50 \mathrm{mg} / \mathrm{m}^{2}\right)$, are awaited. The available results from the other four trials suggest that the expectation of an increased pathological response by adding oxaliplatin to the CRT regimen was not fulfilled; only in the German CAO/ARO/AIO-04 trial a significantly different pathological complete response rate was observed in favour of the arm containing oxaliplatin [55]. Moreover, incorporation of oxaliplatin resulted in significantly higher rates of grade 3 and 4 treatment-related toxicity in three out of four trials that have reported on these data [56-58].

There is a sound theoretical rationale to combine preoperative CRT with each of the targeted agents approved for use in metastatic colorectal cancer (mCRC): cetuximab, panitumumab, and bevacizumab. Epidermal growth factor receptor (EGFR) signaling is associated with proliferation, invasiveness, and metastasis. Several arguments suggest a potential synergism between EGFR inhibition and RT. First, EGFR tyrosine kinase activity is increased in cancer cells in response to RT, and addition of exogenous EGF can induce 


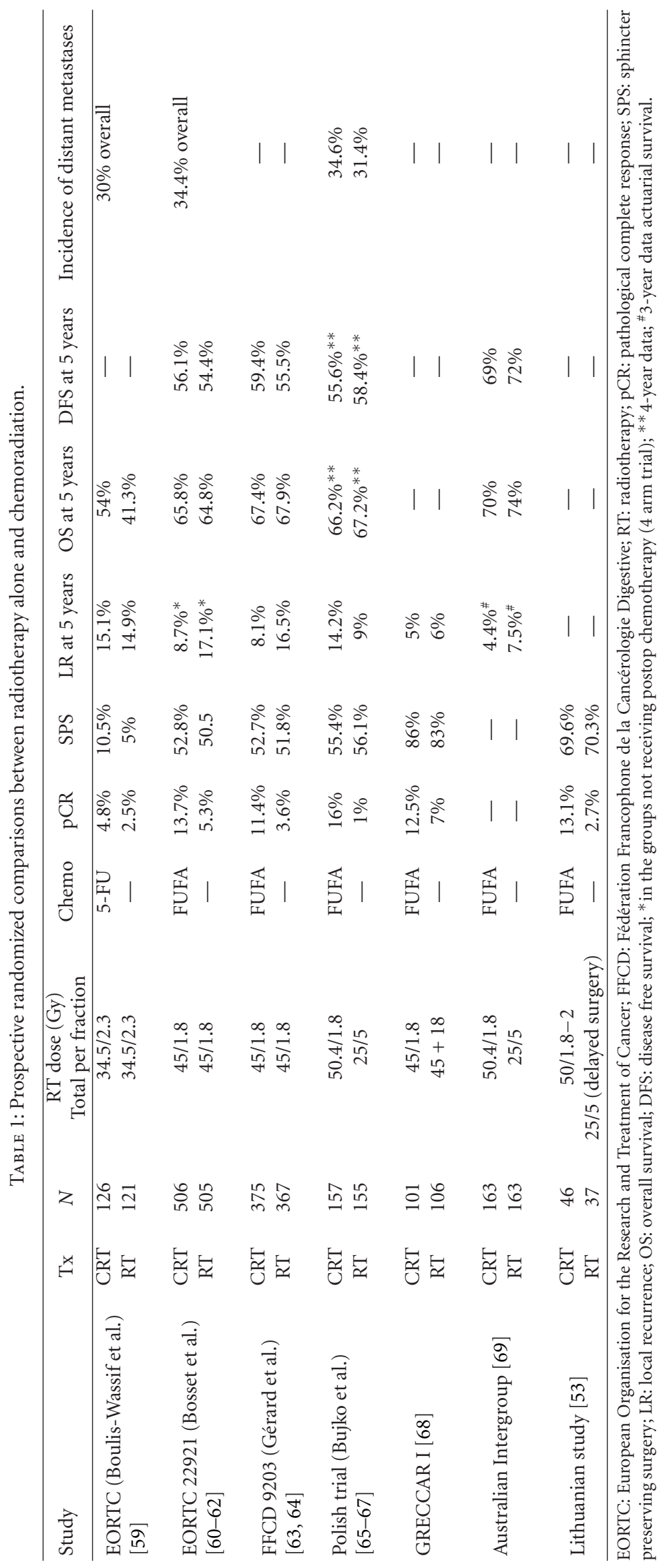


TABLE 2: Interim results of randomized trials incorporating oxaliplatin in preoperative chemoradiation regimens.

\begin{tabular}{|c|c|c|c|c|c|}
\hline Study & Treatment & $N$ & $\begin{array}{c}\text { RT dose (Gy) } \\
\text { Total/per fraction }\end{array}$ & $\mathrm{pCR}$ & SPS \\
\hline \multirow{2}{*}{ STAR01 [56] } & 5-FU CIV & 379 & $50.4 / 1.8$ & $16 \%$ & $80 \%$ \\
\hline & 5 -FU CIV + OX $60 \mathrm{mg} / \mathrm{m}^{2}$ & 368 & $50.4 / 1.8$ & $16 \%$ & $82 \%$ \\
\hline \multirow{2}{*}{ ACCORD 12/0405-Prodige 2 [57] } & CAP $800 \mathrm{mg} / \mathrm{m}^{2}$ & 299 & $45 / 1.8$ & $13.9 \%$ & $75 \%$ \\
\hline & CAP $800 \mathrm{mg} / \mathrm{m}^{2}+$ OX $50 \mathrm{mg} / \mathrm{m}^{2}$ & 299 & $50 / 1.8$ & $19.2 \%$ & $75 \%$ \\
\hline \multirow{2}{*}{ CAO/ARO/AIO-04 [55] } & 5-FU; adj 5-FU & 637 & $50.4 / 1.8$ & $13.1 \%$ & $88.1 \%$ \\
\hline & $5-\mathrm{FU}+\mathrm{OX} 50 \mathrm{mg} / \mathrm{m}^{2}$; adj FolFox 6 & 628 & $50.4 / 1.8$ & $17.6 \%$ & $87.8 \%$ \\
\hline \multirow{2}{*}{ NSABP R-04 [58] } & $5-\mathrm{FU} \mathrm{CIV} \pm \mathrm{OX} 50 \mathrm{mg} / \mathrm{m}^{2}$ & 719 & $50.4 / 1.8$ & $18.8 \%$ & $61.2 \%$ \\
\hline & CAP $825 \mathrm{mg} / \mathrm{m}^{2} \pm$ OX $50 \mathrm{mg} / \mathrm{m}^{2}$ & 707 & $50.4 / 1.8$ & $22.2 \%$ & $62.7 \%$ \\
\hline
\end{tabular}

CAP: capecitabine; RT: radiotherapy; pCR: pathological complete response; SPS: sphincter preserving surgery.

radioresistance in vitro [70]. Second, elevated levels of EGFR expression are an independent adverse prognostic factor in rectal cancer patients [71]. Numerous phase I/II trials have studied incorporation of cetuximab in preoperative CRT schedules. The early results regarding pathological response (pCR rate) are disappointing [72-75]. Interestingly, KRAS mutation, known to be an adverse predictive and prognostic marker in mCRC patients treated with EGFR inhibitors, is less frequent in rectal cancer and does not convey the same predictive information $[76,77]$. The recently reported randomized EXPERT-C trial allocated high-risk rectal cancer patients to four cycles of capecitabine/oxaliplatin (CAPOX) followed by capecitabine CRT, TME surgery, and adjuvant CAPOX or the same regimen plus cetuximab [78]. The primary endpoint was complete (pathological or radiological) response in KRAS/BRAF wild-type tumours. Addition of cetuximab did not affect complete response rate or progression free survival, although it did improve radiological response and overall survival (hazard ratio $0.07-0.99 ; P=$ $0.034)$.

In parallel, efforts have started to combine preoperative CRT regimens with the antiangiogenic agent bevacizumab. Therapy directed against the vascular endothelial growth factor (VEGF) causes "normalization" of the tumour vascular bed, that is, the return to a functionally and morphologically less deficient microvascular network $[79,80]$. This phenomenon is accompanied by increased oxygenation and a decrease in tissue interstitial fluid pressure (IFP). Moreover, it was shown in vitro that RT induces tumour VEGF expression and protects tumour blood vessels from RT-mediated cytotoxicity [81]. Numerous phase I/II trials have studied the integration of bevacizumab into CRT regimens [82-91]. The addition of bevacizumab appears to enhance pathological response rates but is associated with increased treatment related and postoperative complications including wound dehiscence, bowel perforation, and bleeding $[92,93]$. Of note, several imaging (blood flow, perfusion) and molecular biomarkers (soluble VEGF receptor, VEGF, placental derived growth factor, IL-6, and circulating endothelial cells) were shown to correlate with outcome after bevacizumab-based combined modality therapy [91].

\section{Novel Chemotherapy Treatment Strategies}

A consistent finding of the myriad of neoadjuvant radiotherapy containing trials is that hardly any progress has been made in improving overall survival. Consequently, strategies are investigated that aim at delivering more efficient systemic therapy early in the course of therapy. These strategies include induction chemotherapy followed by CRT, and CRT followed by consolidation chemotherapy in the waiting period to surgery. Intensive preoperative chemotherapy not only has the potential to eradicate subclinical metastatic disease but also avoids the inherent compliance problems of postoperative chemotherapy. Several phase II trials have now generated results of neoadjuvant chemotherapy (NACT) followed by CRT (Table 3). Although the survival data seem promising, the two randomized phase II studies comparing upfront CRT with NACT followed by CRT failed to demonstrate improvements in either pCR rate or R0 resection probability [94, 95]. Investigators from the AVACROSS study, who incorporated bevacizumab in both the NACT and CRT regimens, found an impressive pCR rate $36 \%$ while $98 \%$ of patients were able to undergo an R0 resection [96]. However, with a reoperation rate of $24 \%$ and anastomotic leakage rate of $17 \%$, surgical morbidity appears a significant problem when intensifying preoperative regimens with antiangiogenic agents.

An alternative approach is to administer "consolidation" chemotherapy during the waiting period to surgery. Preliminary data were provided by Habr-Gama et al., who treated rectal cancer patients with $54 \mathrm{~Gy}$ of RT with 5FU/leucovorin followed by an additional three cycles of 5$\mathrm{FU} /$ leucovorin; clinical response was assessed ten weeks after completion of CRT [97]. Fourteen out of 29 patients (48\%) were found to have a complete clinical response, while an additional $17 \%$ had a ypT0 stage after local excision. GarciaAguilar and coworkers in a nonrandomized phase II trial compared 5-FU based neoadjuvant CRT with a regimen that added two cycles of FolFox in patients who had a clinical response four weeks after CRT [98]. They found a modest increase in pCR rate $(25 \%$ versus $18 \%)$; whether this is an effect of prolonging the waiting period from 6 


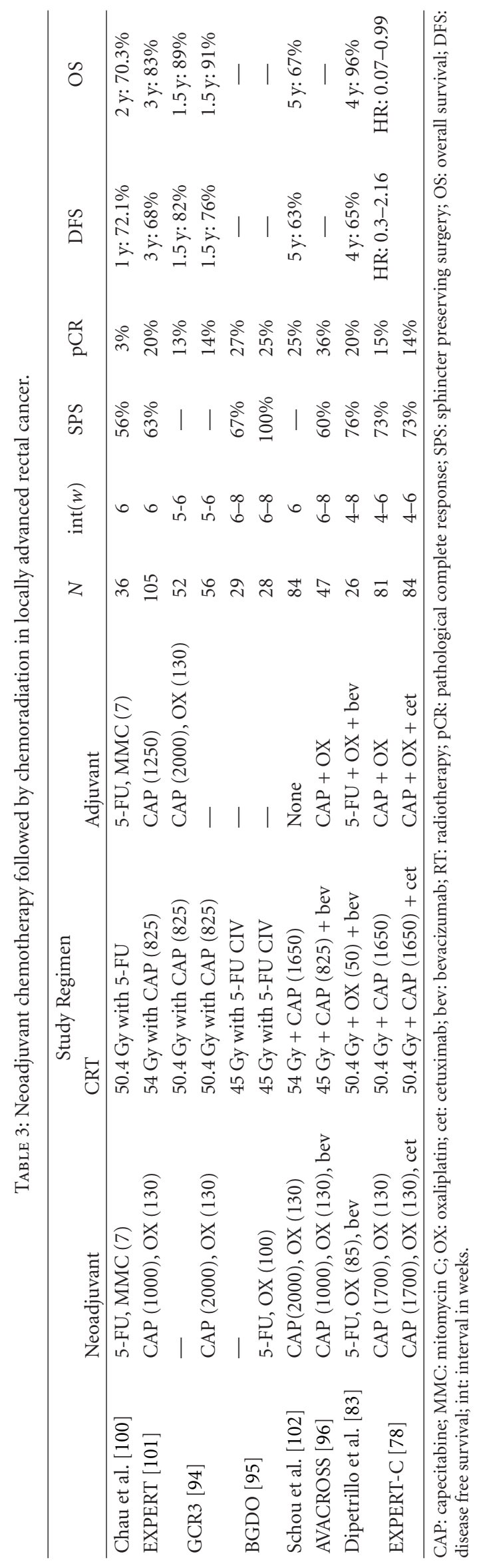


to 11 weeks or of the consolidation chemotherapy cannot be discerned. Important answers will be provided by the ongoing phase III RAPIDO trial (NCT01558921), which will randomize high-risk rectal cancer patients to undergo either neoadjuvant SCRT followed by six cycles of CapOx, or standard neoadjuvant chemoradiation. Intriguingly, recent reports suggest that modern neoadjuvant combination chemotherapy may result in effective downstaging even without any radiotherapy. Schrag reported on a group of patients with resectable rectal cancer who received induction chemotherapy (FolFox with bevacizumab) and were planned to undergo additional CRT or immediate surgery depending on clinical regression [99]. Interestingly, all of the 29 treated patients underwent surgery without CRT and an impressive pCR rate of $27 \%$ was noted. No local recurrences were observed, and three patients (10\%) developed distant metastases (all pulmonary).

\section{Adjuvant Chemotherapy}

At present, it is unclear how patients who underwent neoadjuvant combined modality therapy should be selected for adjuvant chemotherapy. In contrast to colon cancer, there are no randomized adjuvant therapy trials in rectal cancer. A recent Cochrane meta-analysis, based on data concerning patients from trials including both colon and rectal cancer, showed that 5-FU-based adjuvant chemotherapy following curative resection of rectal cancer confers a significant advantage in terms of overall ( $\mathrm{HR}=0.83,95 \%$ CI: $0.76-0.91$ ) and disease-free (HR $=0.75,95 \%$ CI: $0.68-0.83)$ survival although significant heterogeneity between trials was noted [118]. Unfortunately, due to limitations of the source data, the authors were unable to identify those TNM stages that benefit most from adjuvant chemotherapy. One of the included trials in the Cochrane meta-analysis assigned colon and rectal cancer patients at low risk of recurrence (90\% stage II) to either adjuvant 5-FU/folinic acid or observation [119]. Interestingly, planned subgroup analysis showed that the relative risk of recurrence within 2 years was lower in rectal cancer ( $29 \%$ of patients) than in colon cancer patients (RR $0.38-0.89$ and $0.54-0.92$, resp.). Based on these data, it seems reasonable to offer adjuvant chemotherapy to rectal cancer patients based on similar criteria as in colon cancer. However, matters are complicated by the fact that nowadays most rectal cancer patients are treated with neoadjuvant regimens, and uncertainty persists regarding the benefit of adjuvant therapy in patients who have a complete or near complete pathological response. On the one hand, patients with a pathological complete response have a significantly better outlook. In a recent pooled analysis using individual patient data, 5-year disease-free survival was $83.3 \%$ for patients with pCR and $65.6 \%$ for those without pCR (HR 0.44, 95\% CI 0.34-0.57; $P<0.0001$ ) [120]. On the other hand, (unplanned) subgroup analysis of the four-arm EORTC 22921 trial suggested that, while adjuvant chemotherapy did not affect outcome in the whole study population irrespective of whether preoperative RT or CRT was administered, adjuvant chemotherapy significantly improved survival in
ypT0-2 patients (but not in ypT3-4) [121]. However, the generalizability of this finding has been questioned on methodological grounds; moreover, in none of the other three randomized trials exploring adjuvant chemotherapy in patients who received preoperative (C)RT has any benefit been detected $[119,122-124]$. Clearly, therefore, the role of 5-FU-based adjuvant therapy in patients who received chemotherapy containing neoadjuvant regimens remains undefined. Only one prospective randomized trial (SCRIPT, Simply Capecitabine in Rectal cancer after Irradiation Plus TME surgery) by the Dutch colorectal cancer group is testing adjuvant chemotherapy versus observation in rectal cancer patients who received neoadjuvant RT or CRT.

\section{Innovation in Radiation Techniques}

One of the insights gained in the radiobiology of rectal cancer over the past years is that a biologically effective dose (BED) of at least 30 Gray needs to be administered in order to affect the risk of local recurrence [43, 125]. The pathological complete response rates obtained with modern chemoradiation schedules are in the order of 10 $15 \%$. Efforts have been directed to enhance the therapeutic index of radiotherapy by increasing conformity to the target tissue. Highly conformal techniques such as intensity modulated radiotherapy (IMRT), intensity modulated arc therapy (IMAT), and tomotherapy were shown to result in clinically significant reductions in GI toxicity by limiting the dose delivered to the small bowel [126-130]. An interesting option is endocavitary contact radiotherapy, which may completely sterilize early (T1N0 and T2N0) rectal tumours and was shown to result in significant improvements in pCR and sphincter preservation rates when combined with external beam radiotherapy [131-134]. The technique had fallen into disuse over the last years due to the fact that the apparatus was no longer produced. Recently, however, another manufacturer has brought a novel machine on the market (Papillon 50, Ariane Medical Systems, Derby, UK). Several international trials (Contact Endoscopic Microsurgery, CONTEM 1-3) were recently initiated using a combination of contact endocavitary RT with transanal microsurgery, CRT, or standard TME in patients with T1, T2, or early T3 rectal tumours $[135,136]$.

\section{Organ Preservation in Rectal Cancer}

In analogy to current practice in cancer of the anal canal, definitive chemoradiation combined with local excision or without further surgery is under active scrutiny $[137,138]$. There are, nevertheless, several major hurdles to be taken before the concept of organ preservation will gain wide acceptance. First, clearly the adenocarcinoma of the rectum is a much less radiosensitive tumour, and pathological response rates tend to be even lower in general practice compared to what is achieved in the setting of clinical trials [139]. Second, clinical as well as endoscopic and iconographic restagings after CRT are notoriously unreliable, and even post-CRT biopsies are inaccurate in predicting sterilization of both 


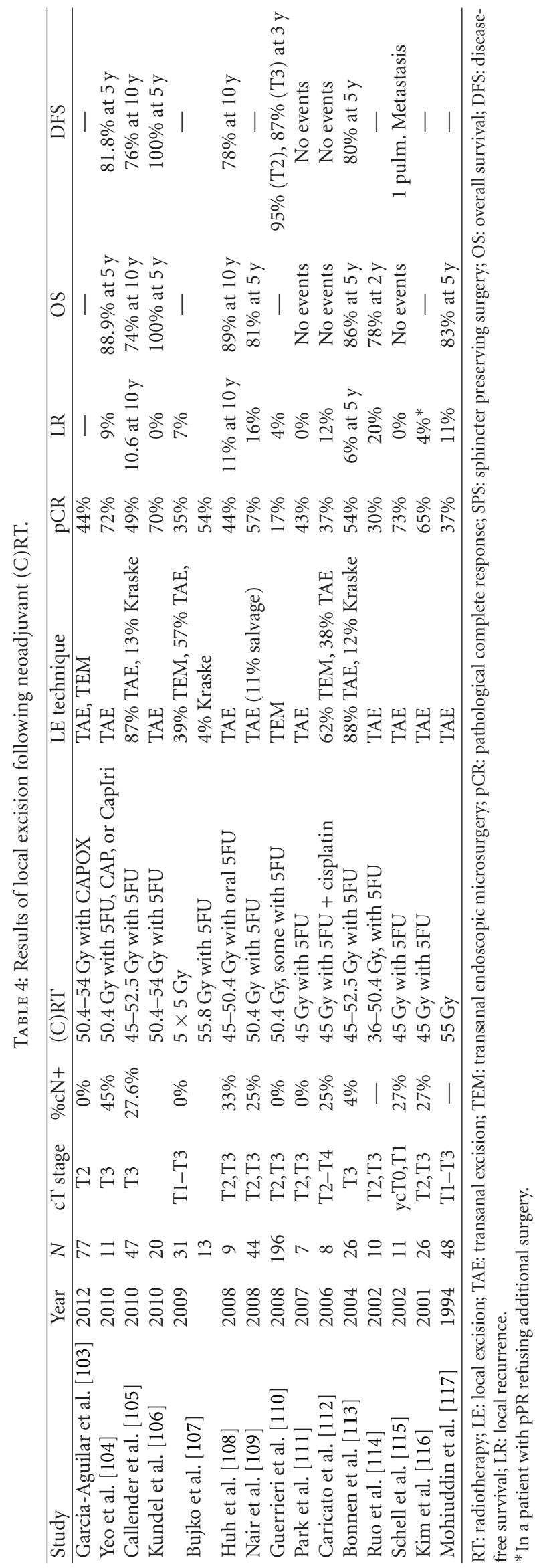


the tumour and the mesorectal nodes [140-143]. Clearly, therefore, a mere "wait and see" approach should currently only be considered in patients unfit for or refusing surgery. There may be a role for local excision in patients who have a substantial clinical response after chemoradiation. Several retrospective reports and small prospective trials have shown impressive pCR rates in early rectal cancers, while both local control and long-term survivals seem excellent (Table 4). Although local excision techniques certainly present less surgical risks compared to resectional procedures, it should be emphasized that they may carry their own specific morbidity such as significant pain after TEM [144]. Also, the results of these preliminary data based on a highly selected population need to be confirmed in prospective controlled trials. The multicenter CARTS trial in The Netherlands will investigate the feasibility of neoadjuvant CRT (25 fractions of $2 \mathrm{~Gy}$ with concurrent capecitabine) followed by transanal endoscopic microsurgery (TEM) in patients with clinical stage $\mathrm{T} 1-3, \mathrm{~N} 0$ rectal cancer below $10 \mathrm{~cm}$ from the anal verge [145]. The French multicenter Groupe de Recherche Chirurgicale sur le Cancer du Rectum (GRECCAR) 2 trial (NCT00427375) will treat rectal cancer patients with a tumor $4 \mathrm{~cm}$ or less in diameter with neoadjuvant CRT. After a 68 -week waiting period, patients in whom the tumour has downstaged to $2 \mathrm{~cm}$ or less will be allocated the either local excision or TME. A polish multicenter trial (NCT00738790) will randomize patients with cT1-3, N0 rectal cancer patients to either short course RT $(5 \times 5$ Gy with a 4 Gy boost after 1 week) or CRT followed by local excision after 6 weeks. A Spanish trial (NCT01308190) will compare in a randomized trial primary TME with CRT followed by local excision in patients with clinically staged $\mathrm{T} 2$ or superficial $\mathrm{T} 3$ low rectal cancer.

Clearly, the adaptation of local resection strategies will depend on our ability to predict the extent of pathological response using clinical, molecular, and imaging biomarkers. Novel imaging techniques such as diffusion-weighted magnetic resonance imaging hold promise in the identification of responders [146-151]. Similarly, gene expression profiling has recently been successfully used to predict pathological response to CRT. Ghadimi et al., using cDNA material obtained during the German CAO/ARO/AIO-94 trial, found that a 54 gene signature correctly predicted response in $83 \%$ of patients [152]. Similar results were reported by Brettingham-Moore and coworkers, although this group was unable to validate previously published gene expression based classifiers in their patient cohort, illustrating the difficulty in comparing and generalizing the use of these classifiers due to the high dimensionality of the data [153]. Several other molecular, genetic, and chromosomal biomarkers of response to CRT in rectal cancer have been identified, and these biomarkers are increasingly integrated into clinical trial design [154-160].

\section{Acknowledgment}

W. Ceelen is a Senior Clinical Researcher with the Fund for Scientific Research-Flanders (FWO).

\section{References}

[1] A. S. Galler, N. J. Petrelli, and S. P. Shakamuri, "Rectal cancer surgery: a brief history," Surgical Oncology, vol. 20, no. 4, pp. 223-230, 2011.

[2] V. Lemmens, L. V. Steenbergen, M. Janssen-Heijnen, H. Martijn, H. Rutten, and J. W. Coebergh, "Trends in colorectal cancer in the south of the Netherlands 19752007: rectal cancer survival levels with colon cancer survival," Acta Oncologica, vol. 49, no. 6, pp. 784-796, 2010.

[3] E. Pihl, E. S. R. Hughes, F. T. McDermott, W. R. Johnson, and H. Katrivessis, "Lung recurrence after curative surgery for colorectal cancer," Diseases of the Colon and Rectum, vol. 30, no. 6, pp. 417-419, 1987.

[4] R. Kirke, A. Rajesh, R. Verma, and M. J. G. Bankart, "Rectal cancer: incidence of pulmonary metastases on thoracic CT and correlation with T staging," Journal of Computer Assisted Tomography, vol. 31, no. 4, pp. 569-571, 2007.

[5] H. Nozawa, E. Sunami, J. Nakajima, H. Nagawa, and J. Kitayama, "Synchronous and metachronous lung metastases in patients with colorectal cancer: a 20-year monocentric experience," Experimental and Therapeutic Medicine, vol. 3, no. 3, pp. 449-456, 2012.

[6] D. Adeyemo and R. Hutchinson, "Preoperative staging of rectal cancer: pelvic MRI plus abdomen and pelvic CT. Does extrahepatic abdomen imaging matter? A case for routine thoracic CT," Colorectal Disease, vol. 11, no. 3, pp. 259-263, 2009.

[7] D. R. Adams, G. J. Blatchford, K. M. Lin, C. A. Ternent, A. G. Thorson, and M. A. Christensen, "Use of preoperative ultrasound staging for treatment of rectal cancer," Diseases of the Colon and Rectum, vol. 42, no. 2, pp. 159-166, 1999.

[8] S. R. Puli, M. L. Bechtold, J. B. K. Reddy, A. Choudhary, M. R. Antillon, and W. R. Brugge, "How good is endoscopic ultrasound in differentiating various $t$ stages of rectal cancer? Meta-analysis and systematic review," Annals of Surgical Oncology, vol. 16, no. 2, pp. 254-265, 2009.

[9] J. Evans, U. Patel, and G. Brown, "Rectal cancer: primary staging and assessment after chemoradiotherapy," Seminars in Radiation Oncology, vol. 21, no. 3, pp. 169-177, 2011.

[10] J. M. Fowler, C. E. Beagley, L. Blomqvist et al., "Extramural depth of tumor invasion at thin-section MR in patients with rectal cancer: results of the MERCURY study," Radiology, vol. 243, no. 1, pp. 132-139, 2007.

[11] G. Brown, I. R. Daniels, R. J. Heald et al., "Diagnostic accuracy of preoperative magnetic resonance imaging in predicting curative resection of rectal cancer: prospective observational study," British Medical Journal, vol. 333, no. 7572, pp. 779-782, 2006.

[12] G. Brown, A. G. Radcliffe, R. G. Newcombe, N. S. Dallimore, M. W. Bourne, and G. T. Williams, "Preoperative assessment of prognostic factors in rectal cancer using high-resolution magnetic resonance imaging," British Journal of Surgery, vol. 90, no. 3, pp. 355-364, 2003.

[13] D. M. Koh, G. Brown, L. Temple et al., "Rectal cancer: mesorectal lymph nodes at MR imaging with USPIO versus histopathologic findings-initial observations," Radiology, vol. 231, no. 1, pp. 91-99, 2004.

[14] D. M. Koh, C. George, L. Temple et al., "Diagnostic accuracy of nodal enhancement pattern of rectal cancer at MRI enhanced with ultrasmall superparamagnetic iron oxide: findings in pathologically matched mesorectal lymph nodes," American Journal of Roentgenology, vol. 194, no. 6, pp. W505W513, 2010. 
[15] G. L. Beets, M. Lahaye, S. M. E. Engelen et al., "Can we predict the nodal status in primary rectal cancer accurately with USPIO MRI?" EJC Supplements, vol. 5, no. 4, pp. 236236, 2007.

[16] D. M. J. Lambregts, G. L. Beets, M. Maas et al., "Accuracy of gadofosveset-enhanced MRI for nodal staging and restaging in rectal cancer," Annals of Surgery, vol. 253, no. 3, pp. 539545, 2011.

[17] A. Chagnac, P. Herskovitz, T. Weinstein et al., "The peritoneal membrane in peritoneal dialysis patients: estimation of its functional surface area by applying stereologic methods to computerized tomography scans," Journal of the American Society of Nephrology, vol. 10, no. 2, pp. 342-346, 1999.

[18] J. Witowski, K. Ksiazek, C. Warnecke et al., "Role of mesothelial cell-derived granulocyte colony-stimulating factor in interleukin-17-induced neutrophil accumulation in the peritoneum," Kidney International, vol. 71, no. 6, pp. 514525, 2007.

[19] K. Bujko, A. Rutkowski, G. J. Chang, W. Michalski, E. Chmielik, and J. Kusnierz, "Is the 1-cm rule of distal bowel resection margin in rectal cancer based on clinical evidence? A systematic review," Annals of Surgical Oncology, vol. 19, no. 3, pp. 801-808, 2012.

[20] A. Rutkowski, M. Chwalinski, J. Oledzki et al., "Safe length of distal bowel margin in lower rectum cancer surgery," Diseases of the Colon \& Rectum, vol. 53, no. 4, pp. 544-544, 2010.

[21] R. J. Heald, E. M. Husband, and R. D. H. Ryall, "The mesorectum in rectal cancer surgery-the clue to pelvic recurrence?" British Journal of Surgery, vol. 69, no. 10, pp. 613-616, 1982.

[22] R. J. Heald and R. D. H. Ryall, "Recurrence and survival after total mesorectal excision for rectal cancer," The Lancet, vol. 1, no. 8496, pp. 1479-1482, 1986.

[23] P. Quirke, M. F. Dixon, P. Durdey, and N. S. Williams, "Local recurrence of rectal adenocarcinoma due to inadequate surgical resection. Histopathological study of lateral tumour spread and surgical excision," The Lancet, vol. 2, no. 8514, pp. 996-999, 1986.

[24] P. Quirke, P. Durdey, N. S. Williams, and M. F. Dixon, "Local recurrence after surgery for rectal adenocarcinoma results from incomplete removal," The Journal of Pathology, vol. 149, no. 3, p. A228, 1986.

[25] A. Korzets, Y. Ori, D. Zevin et al., "A worrying thoughtcould there be a connection between encapsulating peritoneal sclerosis, tamoxifen and calciphylaxis?" Nephrology Dialysis Transplantation, vol. 21, no. 10, pp. 2975-2978, 2006.

[26] R. Schiessel, G. Novi, B. Holzer et al., "Technique and long-term results of intersphincteric resection for low rectal cancer," Diseases of the Colon and Rectum, vol. 48, no. 10, pp. 1858-1865, 2005.

[27] E. Rullier, C. Laurent, F. Bretagnol, A. Rullier, V. Vendrely, and F. Zerbib, "Sphincter-saving resection for all rectal carcinomas: the end of the $2-\mathrm{cm}$ distal rule," Annals of Surgery, vol. 241, no. 3, pp. 465-469, 2005.

[28] A. Chagnac, P. Herskovitz, Y. Ori et al., "Effect of increased dialysate volume on peritoneal surface area among peritoneal dialysis patients," Journal of the American Society of Nephrology, vol. 13, no. 10, pp. 2554-2559, 2002.

[29] S. T. Martin, H. M. Heneghan, and D. C. Winter, "Systematic review of outcomes after intersphincteric resection for low rectal cancer," British Journal of Surgery, vol. 99, no. 5, pp. 603-612, 2012.
[30] N. P. West, C. Anderin, K. J. E. Smith, T. Holm, P. Quirke, and E. Extralevator, "Multicentre experience with extralevator abdominoperineal excision for low rectal cancer," British Journal of Surgery, vol. 97, no. 4, pp. 588-599, 2010.

[31] N. P. West, P. J. Finan, C. Anderin, J. Lindholm, T. Holm, and P. Quirke, "Evidence of the oncologic superiority of cylindrical abdominoperineal excision for low rectal cancer," Journal of Clinical Oncology, vol. 26, no. 21, pp. 3517-3522, 2008.

[32] S. Stelzner, C. Koehler, J. Stelzer, A. Sims, and H. Witzigmann, "Extended abdominoperineal excision vs. standard abdominoperineal excision in rectal cancer-a systematic overview," International Journal of Colorectal Disease, vol. 26, no. 10, pp. 1227-1240, 2011.

[33] Y. Liang, G. Li, P. Chen, and J. Yu, "Laparoscopic versus open colorectal resection for cancer: a meta-analysis of results of randomized controlled trials on recurrence," European Journal of Surgical Oncology, vol. 34, no. 11, pp. 1217-1224, 2008.

[34] E. Kuhry, W. Schwenk, R. Gaupset, U. Romild, and J. Bonjer, "Long-term outcome of laparoscopic surgery for colorectal cancer: a cochrane systematic review of randomised controlled trials," Cancer Treatment Reviews, vol. 34, no. 6, pp. 498-504, 2008.

[35] G. Nandakumar and J. W. Fleshman, "Laparoscopy for rectal cancer," Surgical Oncology Clinics of North America, vol. 19, no. 4, pp. 793-802, 2010.

[36] H. J. Bonjer, A. M. Lacy, E. Haglind et al., "Color II. A randomized clinical trial comparing laparoscopic and open surgery for rectal cancer," Danish Medical Bulletin, vol. 56, no. 2, pp. 89-91, 2009.

[37] S. Kitano, M. Inomata, A. Sato, K. Yoshimura, and Y. Moriya, "Randomized controlled trial to evaluate laparoscopic surgery for colorectal cancer: Japan clinical oncology group study JCOG 0404," Japanese Journal of Clinical Oncology, vol. 35, no. 8, pp. 475-477, 2005.

[38] S. H. Baik, M. Gincherman, M. G. Mutch, E. H. Birnbaum, and J. W. Fleshman, "Laparoscopic vs open resection for patients with rectal cancer: comparison of perioperative outcomes and long-term survival," Diseases of the Colon and Rectum, vol. 54, no. 1, pp. 6-14, 2011.

[39] H. J. Bonjer, E. Haglind, M. A. Cuesta, A. Fürst, van der Pas MHGM, and W. C. J. Hop, "Laparoscopic surgery versus open surgery for rectal cancer: short term outcomes of a randomized trial," in Proceedings of the European Cancer Organisation (ECCO '11), Stockholm, Sweden, 2011.

[40] H. S. Tilney and P. P. Tekkis, "Extending the horizons of restorative rectal surgery: intersphincteric resection for low rectal cancer," Colorectal Disease, vol. 10, no. 1, pp. 3-15, 2008.

[41] R. Gray, R. Hills, R. Stowe et al., "Adjuvant radiotherapy for rectal cancer: a systematic overview of 8507 patients from 22 randomised trials," The Lancet, vol. 358, no. 9290, pp. 12911304, 2001.

[42] R. Sauer, H. Becker, W. Hohenberger et al., "Preoperative versus postoperative chemoradiotherapy for rectal cancer," New England Journal of Medicine, vol. 351, no. 17, pp. 17311740, 2004

[43] R. Suwinski, J. M. G. Taylor, and H. R. Withers, "Rapid growth of microscopic rectal cancer as a determinant of response to preoperative radiation therapy," International Journal of Radiation Oncology Biology Physics, vol. 42, no. 5, pp. 943-951, 1998. 
[44] G. A. Viani, E. J. Stefano, F. V. Soares, and S. L. Afonso, "Evaluation of biologic effective dose and schedule of fractionation for preoperative radiotherapy for rectal cancer: meta-analyses and meta-regression," International Journal of Radiation Oncology Biology Physics, vol. 80, no. 4, pp. 985991, 2011.

[45] E. Kapiteijn, C. A. M. Marijnen, I. D. Nagtegaal et al., "Preoperative radiotherapy combined with total mesorectal excision for resectable rectal cancer," New England Journal of Medicine, vol. 345, no. 9, pp. 638-646, 2001.

[46] W. Van Gijn, C. A. M. Marijnen, I. D. Nagtegaal et al., "Preoperative radiotherapy combined with total mesorectal excision for resectable rectal cancer: 12-year follow-up of the multicentre, randomised controlled TME trial," The Lancet Oncology, vol. 12, no. 6, pp. 575-582, 2011.

[47] C. A. M. Marijnen, I. D. Nagtegaal, E. Kapiteijn et al., "Radiotherapy does not compensate for positive resection margins in rectal cancer patients: report of a multicenter randomized trial," International Journal of Radiation Oncology Biology Physics, vol. 55, no. 5, pp. 1311-1320, 2003.

[48] W. Ceelen, K. Fierens, Y. Van Nieuwenhove, and P. Pattyn, "Preoperative chemoradiation versus radiation alone for stage II and III resectable rectal cancer: a systematic review and meta-analysis," International Journal of Cancer, vol. 124, no. 12, pp. 2966-2972, 2009.

[49] H. Birgisson, L. Påhlman, U. Gunnarsson, and B. Glimelius, "Occurrence of second cancers in patients treated with radiotherapy for rectal cancer," Journal of Clinical Oncology, vol. 23, no. 25, pp. 6126-6131, 2005.

[50] H. Birgisson, L. Påhlman, U. Gunnarsson, and B. Glimelius, "Late gastrointestinal disorders after rectal cancer surgery with and without preoperative radiation therapy," British Journal of Surgery, vol. 95, no. 2, pp. 206-213, 2008.

[51] M. M. Lange, M. Den Dulk, E. R. Bossema et al., "Risk factors for faecal incontinence after rectal cancer treatment," British Journal of Surgery, vol. 94, no. 10, pp. 1278-1284, 2007.

[52] M. M. Lange, C. A. M. Marijnen, C. P. Maas et al., "Risk factors for sexual dysfunction after rectal cancer treatment," European Journal of Cancer, vol. 45, no. 9, pp. 1578-1588, 2009.

[53] T. Latkauskas, H. Pauzas, I. Gineikiene et al., "Initial results of a randomized controlled trial comparing clinical and pathological downstaging of rectal cancer after preoperative short-course radiotherapy or long-term chemoradiotherapy, both with delayed surgery," Colorectal Disease, vol. 14, no. 3, pp. 294-298, 2012.

[54] D. Pettersson, B. Cederniark, T. Holm et al., "Interim analysis of the Stockholm III trial of preoperative radiotherapy regimens for rectal cancer," British Journal of Surgery, vol. 97, no. 4 , pp. 580-587, 2010.

[55] C. Roedel, "Preoperative chemoradiotherapy and postoperative chemotherapy with 5 -fluorouracil and oxaliplatin versus 5-fluorouracil alone in locally advanced rectal cancer: first results of the German CAO/ARO/AIO-04 randomized phase III trial," Journal of Clinical Oncology, vol. 29, supplement, abstract LBA3505, 2011.

[56] C. Aschele, L. Cionini, S. Lonardi et al., "Primary tumor response to preoperative chemoradiation with or without oxaliplatin in locally advanced rectal cancer: pathologic results of the STAR-01 randomized phase III trial," Journal of Clinical Oncology, vol. 29, no. 20, pp. 2773-2780, 2011.

[57] J. P. Gérard, D. Azria, S. Gourgou-Bourgade et al., "Comparison of two neoadjuvant chemoradiotherapy regimens for locally advanced rectal cancer: results of the phase III trial accord 12/0405-Prodige 2," Journal of Clinical Oncology, vol. 28, no. 10, pp. 1638-1644, 2010.

[58] M. S. Roh, "The impact of capecitabine and oxaliplatin in the preoperative multimodality treatment in patients with carcinoma of the rectum: NSABP R-04," Journal of Clinical Oncology, vol. 29, supplement, abstract 3503, 2011.

[59] S. Boulis-Wassif, A. Gerard, and J. Loygue, "Final results of a randomized trial on the treatment of rectal cancer with preoperative radiotherapy alone or in combination with 5-fluorouracil, followed by radical surgery. Trial of the European Organization on Research and Treatment of Cancer gastrointestinal tract cancer cooperative group," Cancer, vol. 53, no. 9, pp. 1811-1818, 1984.

[60] J. F. Bosset, L. Collette, G. Calais et al., "Chemotherapy with preoperative radiotherapy in rectal cancer," New England Journal of Medicine, vol. 355, no. 11, pp. 1114-1123, 2006.

[61] J. F. Bosset, G. Calais, L. Mineur et al., "Enhanced tumorocidal effect of chemotherapy with preoperative radiotherapy for rectal cancer: preliminary results_EORTC 22921," Journal of Clinical Oncology, vol. 23, no. 24, pp. 5620-5627, 2005.

[62] J. F. Bosset, G. Calais, A. Daban et al., "Preoperative chemoradiotherapy versus preoperative radiotherapy in rectal cancer patients: assessment of acute toxicity and treatment compliance: report of the 22921 randomised trial conducted by the EORTC Radiotherapy Group," European Journal of Cancer, vol. 40, no. 2, pp. 219-224, 2004.

[63] J. P. Gérard, T. Conroy, F. Bonnetain et al., "Preoperative radiotherapy with or without concurrent fluorouracil and leucovorin in T3-4 rectal cancers: results of FFCD 9203," Journal of Clinical Oncology, vol. 24, no. 28, pp. 4620-4625, 2006.

[64] J. Gerard, T. Conroy, F. Bonnetain et al., "Preoperative (Preop) radiotherapy (RT) plus FU/folinic acid (FA) in T3.4 rectal cancers: preliminary results of the FFCD 9203 randomized trial," Journal of Radiation Oncology Biology Physics, vol. 60, no. 1, p. S138, 2004

[65] K. Bujko, M. P. Nowacki, A. Nasierowska-Guttmejer et al., "Sphincter preservation following preoperative radiotherapy for rectal cancer: report of a randomised trial comparing short-term radiotherapy vs. conventionally fractionated radiochemotherapy," Radiotherapy and Oncology, vol. 72, no. 1, pp. 15-24, 2004.

[66] K. Bujko, M. P. Nowacki, A. Nasierowska-Guttmejer, W. Michalski, M. Bebenek, and M. Kryj, "Long-term results of a randomized trial comparing preoperative short-course radiotherapy with preoperative conventionally fractionated chemoradiation for rectal cancer," British Journal of Surgery, vol. 93, no. 10, pp. 1215-1223, 2006.

[67] K. Bujko, M. P. Nowacki, A. Nasierowska-Guttmejer et al., "Prediction of mesorectal nodal metastases after chemoradiation for rectal cancer: results of a randomised trial. Implication for subsequent local excision," Radiotherapy and Oncology, vol. 76, no. 3, pp. 234-240, 2005.

[68] P. Rouanet, M. Rivoire, B. Lelong et al., "Sphincter preserving surgery after preoperative treatment for ultra-low rectal carcinoma. A French multicenter prospective trial: GRECCAR 1," Journal of Clinical Oncology, vol. 24, no. 18, p. 152S, 2006.

[69] S. Ngan, "A randomized trial comparing local recurrence (LR) rates between short-course (SC) and long-course (LC) preoperative radiotherapy (RT) for clinical T3 rectal cancer: an intergroup trial (TROG, AGITG, CSSANZ, RACS)," Journal of Clinical Oncology, vol. 28, 15s, abstract 3509, 2010. 
[70] R. Wollman, J. Yahalom, R. Maxy, J. Pinto, and Z. Fuks, "Effect of epidermal growth factor on the growth and radiation sensitivity of human breast cancer cells in vitro," International Journal of Radiation Oncology Biology Physics, vol. 30, no. 1, pp. 91-98, 1994.

[71] R. Kopp, E. Rothbauer, E. Mueller, F. W. Schildberg, K. W. Jauch, and A. Pfeiffer, "Reduced survival of rectal cancer patients with increased tumor epidermal growth factor receptor levels," Diseases of the Colon and Rectum, vol. 46, no. 10, pp. 1391-1399, 2003.

[72] R. D. Hofheinz, K. Horisberger, C. Woernle et al., "Phase I trial of cetuximab in combination with capecitabine, weekly irinotecan, and radiotherapy as neoadjuvant therapy for rectal cancer," International Journal of Radiation Oncology Biology Physics, vol. 66, no. 5, pp. 1384-1390, 2006.

[73] S. Y. Kim, Y. S. Hong, D. Y. Kim et al., "Preoperative chemoradiation with cetuximab, irinotecan, and capecitabine in patients with locally advanced resectable rectal cancer: a multicenter phase II study," International Journal of Radiation Oncology, Biology, Physics, vol. 81, no. 3, pp. 677-683, 2011.

[74] J. P. Machiels, C. Sempoux, P. Scalliet et al., "Phase I/II study of preoperative cetuximab, capecitabine, and external beam radiotherapy in patients with rectal cancer," Annals of Oncology, vol. 18, no. 4, pp. 738-744, 2007.

[75] C. Rödel, D. Arnold, M. Hipp et al., "Phase I-II trial of cetuximab, capecitabine, oxaliplatin, and radiotherapy as preoperative treatment in rectal cancer," International Journal of Radiation Oncology Biology Physics, vol. 70, no. 4, pp. 1081-1086, 2008.

[76] S. Y. Kim, Y. S. Hong, D. Y. Kim et al., "Preoperative chemoradiation with cetuximab, irinotecan, and capecitabine in patients with locally advanced resectable rectal cancer: a multicenter phase II study," International Journal of Radiation Oncology, Biology, Physics, vol. 81, no. 3, pp. 677-683, 2011.

[77] V. Velenik, J. Ocvirk, I. Oblak, and F. Anderluh, "A phase II study of cetuximab, capecitabine and radiotherapy in neoadjuvant treatment of patients with locally advanced resectable rectal cancer," European Journal of Surgical Oncology, vol. 36, no. 3, pp. 244-250, 2010.

[78] A. Dewdney, D. Cunningham, J. Tabernero et al., "Multicenter randomized phase II clinical trial comparing neoadjuvant oxaliplatin, capecitabine, and preoperative radiotherapy with or without cetuximab followed by total mesorectal excision in patients with high-risk rectal cancer (EXPERT-C)," Journal of Clinical Oncology, vol. 30, no. 14, pp. 1620-1627, 2012.

[79] R. P. M. Dings, M. Loren, H. Heun et al., "Scheduling of radiation with angiogenesis inhibitors anginex and avastin improves therapeutic outcome via vessel normalization," Clinical Cancer Research, vol. 13, no. 11, pp. 3395-3402, 2007.

[80] R. K. Jain, "Normalization of tumor vasculature: an emerging concept in antiangiogenic therapy," Science, vol. 307, no. 5706, pp. 58-62, 2005.

[81] D. H. Gorski, M. A. Beckett, N. T. Jaskowiak et al., "Blockade of the vascular endothelial growth factor stress response increases the antitumor effects of ionizing radiation," Cancer Research, vol. 59, no. 14, pp. 3374-3378, 1999.

[82] C. H. Crane, C. Eng, B. W. Feig et al., "Phase II trial of neoadjuvant bevacizumab, capecitabine, and radiotherapy for locally advanced rectal cancer," International Journal of Radiation Oncology Biology Physics, vol. 76, no. 3, pp. 824830, 2010.

[83] T. Dipetrillo, V. Pricolo, J. Lagares-Garcia et al., "Neoadjuvant bevacizumab, oxaliplatin, 5 -fluorouracil, and radiation for rectal cancer," International Journal of Radiation Oncology, Biology, Physics, vol. 82, no. 1, pp. 124-129, 2012.

[84] G. Gasparini, F. Torino, T. Ueno et al., "A phase II study of neoadjuvant bevacizumab plus capecitabine and concomitant radiotherapy in patients with locally advanced rectal cancer," Angiogenesis, vol. 15, no. 1, pp. 141-150, 2012.

[85] T. Hohler, M. Klein, K. Dellas et al., "Preoperative chemoradiation (CRT) with concurrent capecitabine (Cap), oxaliplatin (Ox) and bevacizumab (Bev) in patients with locally advanced rectal cancer (RC): effects on pathological complete response (pCR) and surgical complications," Onkologie, vol. 34, p. 220, 2011.

[86] H. Kennecke, S. Berry, R. Wong et al., "Pre-operative bevacizumab, capecitabine, oxaliplatin and radiation among patients with locally advanced or low rectal cancer: a phase II trial," European Journal of Cancer, vol. 48, no. 1, pp. 37-45, 2012.

[87] G. Resch, A. De Vries, D. Öfner et al., "Preoperative treatment with capecitabine, bevacizumab and radiotherapy for primary locally advanced rectal cancer-a two stage phase II clinical trial," Radiotherapy and Oncology, vol. 102, no. 1, pp. 10-13, 2012.

[88] D. R. Spigel, J. C. Bendell, M. McCleod et al., "Phase II study of bevacizumab and chemoradiation in the preoperative or adjuvant treatment of patients with stage II/III rectal cancer," Clinical Colorectal Cancer, vol. 11, no. 1, pp. 45-52, 2012.

[89] K. Uehara, S. Ishiguro, E. Sakamoto et al., "Phase II trial of neoadjuvant chemotherapy with XELOX plus bevacizumab for locally advanced rectal cancer," Japanese Journal of Clinical Oncology, vol. 41, no. 8, Article ID hyr084, pp. 10411044, 2011.

[90] V. Velenik, J. Ocvirk, M. Music et al., "Neoadjuvant capecitabine, radiotherapy, and bevacizumab (CRAB) in locally advanced rectal cancer: results of an open-label phase II study," Radiation Oncology, vol. 6, article 105, 2011.

[91] C. G. Willett, D. G. Duda, E. Di Tomaso et al., "Efficacy, safety, and biomarkers of neoadjuvant bevacizumab, radiation therapy, and fluorouracil in rectal cancer: a multidisciplinary phase II study," Journal of Clinical Oncology, vol. 27, no. 18, pp. 3020-3026, 2009.

[92] T. Dipetrillo, V. Pricolo, J. Lagares-Garcia et al., "Neoadjuvant bevacizumab, oxaliplatin, 5-fluorouracil, and radiation for rectal cancer," International Journal of Radiation Oncology, Biology, Physics, vol. 82, no. 1, pp. 124-129, 2012.

[93] C. Marijnen, "Preoperative chemoradiotherapy regimen with capecitabine and bevacizumab in locally advanced rectal cancer: a feasibility study of the Dutch Colorectal Cancer Group (DCCG)," Journal of Clinical Oncology, vol. 26, supplement, abstract 15040, 2008.

[94] C. Fernández-Martos, C. Pericay, J. Aparicio et al., "Phase II, randomized study of concomitant chemoradiotherapy followed by surgery and adjuvant capecitabine plus oxaliplatin (CAPOX) compared with induction CAPOX followed by concomitant chemoradiotherapy and surgery in magnetic resonance imaging-defined, locally advanced rectal cancer: Grupo Cáncer de Recto 3 study," Journal of Clinical Oncology, vol. 28 , no. 5, pp. 859-865, 2010.

[95] R. Maréchal, "Chemotherapy induction followed by preoperative chemoradiation versus preoperative chemoradiation alone in locally advanced rectal cancer (LARC): a randomized controlled phase II study," Journal of Clinical Oncology, vol. 28, 15s, abstract 3637, 2010. 
[96] M. Nogué, A. Salud, P. Vicente et al., "Addition of bevacizumab to XELOX induction therapy plus concomitant capecitabine-based chemoradiotherapy in magnetic resonance imaging-defined poor-prognosis locally advanced rectal cancer: the AVACROSS study," Oncologist, vol. 16, no. 5, pp. 614-620, 2011.

[97] A. Habr-Gama, R. O. Perez, J. Sabbaga, W. Nadalin, G. P. São Julião, and J. Gama-Rodrigues, "Increasing the rates of complete response to neoadjuvant chemoradiotherapy for distal rectal cancer: results of a prospective study using additional chemotherapy during the resting period," Diseases of the Colon and Rectum, vol. 52, no. 12, pp. 1927-1934, 2009.

[98] J. Garcia-Aguilar, D. D. Smith, K. Avila, E. K. Bergsland, P. Chu, and R. M. Krieg, "Optimal timing of surgery after chemoradiation for advanced rectal cancer: preliminary results of a multicenter, nonrandomized phase II prospective trial," Annals of Surgery, vol. 254, no. 1, pp. 97-102, 2011.

[99] D. Schrag, "Neoadjuvant FOLFOX-bev, without radiation, for locally advanced rectal cancer," Journal of Clinical Oncology, vol. 28, 15s, abstract 3511, 2010.

[100] I. Chau, M. Allen, D. Cunningham et al., "Neoadjuvant systemic fluorouracil and mitomycin C prior to synchronous chemoradiation is an effective strategy in locally advanced rectal cancer," British Journal of Cancer, vol. 88, no. 7, pp. 1017-1024, 2003.

[101] Y. J. Chua, Y. Barbachano, D. Cunningham et al., "Neoadjuvant capecitabine and oxaliplatin before chemoradiotherapy and total mesorectal excision in MRI-defined poor-risk rectal cancer: a phase 2 trial," The Lancet Oncology, vol. 11, no. 3, pp. 241-248, 2010.

[102] J. V. Schou, F. O. Larsen, L. Rasch et al., "Induction chemotherapy with capecitabine and oxaliplatin followed by chemoradiotherapy before total mesorectal excision in patients with locally advanced rectal cancer," Annals of Oncology. In press.

[103] J. Garcia-Aguilar, Q. Shi, C. R. Thomas et al., "A Phase II trial of neoadjuvant chemoradiation and local excision for T2N0 rectal cancer: preliminary results of the ACOSOG Z6041 trial," Annals of Surgical Oncology, vol. 19, no. 2, pp. 384-391, 2012.

[104] S. G. Yeo, D. Y. Kim, T. H. Kim et al., "Local excision following pre-operative chemoradiotherapyinduced downstaging for selected cT3 distal rectal cancer," Japanese Journal of Clinical Oncology, vol. 40, no. 8, Article ID hyq062, pp. 754760, 2010.

[105] G. G. Callender, P. Das, M. A. Rodriguez-Bigas et al., "Local excision after preoperative chemoradiation results in an equivalent outcome to total mesorectal excision in selected patients with T3 rectal cancer," Annals of Surgical Oncology, vol. 17, no. 2, pp. 441-447, 2010.

[106] Y. Kundel, R. Brenner, O. Purim et al., "Is local excision after complete pathological response to neoadjuvant chemoradiation for rectal cancer an acceptable treatment option?" Diseases of the Colon and Rectum, vol. 53, no. 12, pp. 16241631, 2010.

[107] K. Bujko, P. Richter, M. Kołodziejczyk et al., "Preoperative radiotherapy and local excision of rectal cancer with immediate radical re-operation for poor responders," Radiotherapy and Oncology, vol. 92, no. 2, pp. 195-201, 2009.

[108] J. W. Huh, E. J. Jung, Y. A. Park, K. Y. Lee, and S. K. Sohn, "Preoperative chemoradiation followed by transanal excision for rectal cancer," Journal of Surgical Research, vol. 148, no. 2, pp. 244-250, 2008.
[109] R. M. Nair, E. M. Siegel, D. T. Chen et al., "Long-term results of transanal excision after neoadjuvant chemoradiation for T2 and T3 adenocarcinomas of the rectum," Journal of Gastrointestinal Surgery, vol. 12, no. 10, pp. 1797-1805, 2008.

[110] M. Guerrieri, M. Baldarelli, L. Organetti et al., "Transanal endoscopic microsurgery for the treatment of selected patients with distal rectal cancer: 15 Years experience," Surgical Endoscopy and Other Interventional Techniques, vol. 22, no. 9, pp. 2030-2035, 2008.

[111] C. Park, W. Lee, S. Han, S. Yun, and H. K. Chun, “Transanal local excision for preoperative concurrent chemoradiation therapy for distal rectal cancer in selected patients," Surgery Today, vol. 37, no. 12, pp. 1068-1072, 2007.

[112] M. Caricato, D. Borzomati, F. Ausania et al., "Complementary use of local excision and transanal endoscopic microsurgery for rectal cancer after neoadjuvant chemoradiation," Surgical Endoscopy and Other Interventional Techniques, vol. 20, no. 8, pp. 1203-1207, 2006.

[113] M. Bonnen, C. Crane, J. N. Vauthey et al., "Long-term results using local excision after preoperative chemoradiation among selected T3 rectal cancer patients," International Journal of Radiation Oncology Biology Physics, vol. 60, no. 4, pp. 1098-1105, 2004.

[114] L. Ruo, J. G. Guillem, B. D. Minsky, S. H. Q. Quan, P. B. Paty, and A. M. Cohen, "Preoperative radiation with or without chemotherapy and full-thickness transanal excision for selected T2 and T3 distal rectal cancers," International Journal of Colorectal Disease, vol. 17, no. 1, pp. 54-58, 2002.

[115] S. R. Schell, R. A. Zlotecki, W. M. Mendenhall, R. W. Marsh, J. N. Vauthey, and E. M. Copeland, "Transanal excision of locally advanced rectal cancers downstaged using neoadjuvant chemoradiotherapy," Journal of the American College of Surgeons, vol. 194, no. 5, pp. 584-591, 2002.

[116] C. J. Kim, T. J. Yeatman, D. Coppola et al., "Local excision of T2 and T3 rectal cancers after downstaging chemoradiation," Annals of Surgery, vol. 234, no. 3, pp. 352-359, 2001.

[117] M. Mohiuddin, G. Marks, and J. Bannon, "High-dose preoperative radiation and full thickness local excision: a new option for selected T3 distal rectal cancers," International Journal of Radiation Oncology Biology Physics, vol. 30, no. 4, pp. 845-849, 1994.

[118] S. H. Petersen, H. Harling, L. T. Kirkeby, P. Wille-Jorgensen, and S. Mocellin, "Postoperative adjuvant chemotherapy in rectal cancer operated for cure," Cochrane Database of Systematic Reviews, vol. 3, Article ID CD004078, 2012.

[119] R. Gray, J. Barnwell, C. McConkey et al., "Adjuvant chemotherapy versus observation in patients with colorectal cancer: a randomised study," The Lancet, vol. 370, no. 9604, pp. 2020-2029, 2007.

[120] M. Maas, P. J. Nelemans, V. Valentini et al., "Long-term outcome in patients with a pathological complete response after chemoradiation for rectal cancer: a pooled analysis of individual patient data," The Lancet Oncology, vol. 11, no. 9, pp. 835-844, 2010.

[121] L. Collette, J. F. Bosset, M. Den Dulk et al., "Patients with curative resection of cT3-4 rectal cancer after preoperative radiotherapy or radiochemotherapy: does anybody benefit from adjuvant fluorouracil-based chemotherapy? A trial of the European Organisation for Research and Treatment of Cancer Radiation Oncology Group," Journal of Clinical Oncology, vol. 25, no. 28, pp. 4379-4386, 2007.

[122] K. Bujko, R. Glynne-Jones, and M. Bujko, "Does adjuvant fluoropyrimidine-based chemotherapy provide a benefit for 
patients with resected rectal cancer who have already received neoadjuvant radiochemotherapy? A systematic review of randomised trials," Annals of Oncology, vol. 21, no. 9, pp. 1743-1750, 2010.

[123] L. Cionini, "Randomized study of postoperative chemotherapy (CT) after preoperative chemoradiation (CTRT) in locally advanced rectal cancer (LARC): preliminary results," European Journal of Cancer, vol. 37, supplement 6, p. S300, 2001.

[124] R. Li, "Combination of surgery, radiotherapy and chemotherapy for rectal cancer-a 423 case report," Zhonghua Zhong Liu Za Zhi, vol. 14, no. 3, pp. 213-215, 1992.

[125] R. K. S. Wong, V. Tandan, S. De Silva, and A. Figueredo, "Preoperative radiotherapy and curative surgery for the management of localized rectal carcinoma," Cochrane Database of Systematic Reviews, no. 2, Article ID CD002102, 2007.

[126] S. Cilla, L. Caravatta, V. Picardi et al., "Volumetric modulated arc therapy with simultaneous integrated boost for locally advanced rectal cancer," Clinical Oncology, vol. 24, no. 4, pp. 261-268, 2012.

[127] B. Engels, K. Tournel, H. Everaert et al., "Phase II study of preoperative helical tomotherapy with a simultaneous integrated boost for rectal cancer," International Journal of Radiation Oncology Biology Physics, vol. 83, no. 1, pp. 142148, 2012.

[128] J. M. Samuelian, M. D. Callister, J. B. Ashman, T. M. YoungFadok, M. J. Borad, and L. L. Gunderson, "Reduced acute bowel toxicity in patients treated with intensity-modulated radiotherapy for rectal cancer," International Journal of Radiation Oncology, Biology, Physics, vol. 82, no. 5, pp. 19811987, 2012.

[129] W. Duthoy, W. De Gersem, K. Vergote et al., "Clinical implementation of intensity-modulated arc therapy (IMAT) for rectal cancer," International Journal of Radiation Oncology Biology Physics, vol. 60, no. 3, pp. 794-806, 2004.

[130] B. Engels, M. De Ridder, K. Tournel et al., "Preoperative helical tomotherapy and megavoltage computed tomography for rectal cancer: impact on the irradiated volume of small bowel," International Journal of Radiation Oncology Biology Physics, vol. 74, no. 5, pp. 1476-1480, 2009.

[131] J. P. Gerard, O. Chapet, C. Nemoz et al., "Improved sphincter preservation in low rectal cancer with high-dose preoperative radiotherapy: the Lyon R96-02 randomized trial," Journal of Clinical Oncology, vol. 22, no. 12, pp. 2404-2409, 2004.

[132] J. P. Gerard, O. Chapet, A. Ramaioli, and P. Romestaing, "Long-term control of T2-T3 rectal adenocarcinoma with radiotherapy alone," International Journal of Radiation Oncology Biology Physics, vol. 54, no. 1, pp. 142-149, 2002.

[133] J. P. Gerard, P. Romestaing, J. M. Ardiet, and F. Mornex, "Endocavitary radiation therapy," Seminars in Radiation Oncology, vol. 8, no. 1, pp. 13-23, 1998.

[134] J. P. Gerard, P. Romestaing, and O. Chapet, "Radiotherapy alone in the curative treatment of rectal carcinoma," The Lancet Oncology, vol. 4, no. 3, pp. 158-166, 2003.

[135] J. P. Gérard, A. S. Myint, O. Croce et al., "Renaissance of contact X-ray therapy for treating rectal cancer," Expert Review of Medical Devices, vol. 8, no. 4, pp. 483-492, 2011.

[136] A. S. Myint, "Renaissance of contact radiotherapy with RT 50 Papillon machine: a revival of new treatment option for early low rectal cancer?" Journal of Clinical Oncology, supplement, abstract e14149, 2012.
[137] F. Lim and R. Glynne-Jones, "Chemotherapy/chemoradiation in anal cancer: a systematic review," Cancer Treatment Reviews, vol. 37, no. 7, pp. 520-532, 2011.

[138] A. Habr-Gama, R. O. Perez, G. P. São Julião, I. Proscurshim, and J. Gama-Rodrigues, "Nonoperative approaches to rectal cancer: a critical evaluation," Seminars in Radiation Oncology, vol. 21, no. 3, pp. 234-239, 2011.

[139] P. Sanghera, D. W. Y. Wong, C. C. McConkey, J. I. Geh, and A. Hartley, "Chemoradiotherapy for rectal cancer: an updated analysis of factors affecting pathological response," Clinical Oncology, vol. 20, no. 2, pp. 176-183, 2008.

[140] J. W. Huh, Y. A. Park, E. J. Jung, K. Y. Lee, and S. K. Sohn, "Accuracy of endorectal ultrasonography and computed tomography for restaging rectal cancer after preoperative chemoradiation," Journal of the American College of Surgeons, vol. 207, no. 1, pp. 7-12, 2008.

[141] C. Kristiansen, A. Loft, A. K. Berthelsen et al., "PET/CT and histopathologic response to preoperative chemoradiation therapy in locally advanced rectal cancer," Diseases of the Colon and Rectum, vol. 51, no. 1, pp. 21-25, 2008.

[142] A. Suppiah, I. A. Hunter, J. Cowley et al., "Magnetic resonance imaging accuracy in assessing tumour downstaging following chemoradiation in rectal cancer," Colorectal Disease, vol. 11, no. 3, pp. 249-253, 2009.

[143] R. O. Perez, A. Habr-Gama, G. V. Pereira et al., "Role of biopsies in patients with residual rectal cancer following neoadjuvant chemoradiation after downsizing: can they rule out persisting cancer?" Colorectal Disease, vol. 14, no. 6, pp. 714-720, 2012.

[144] R. O. Perez, A. Habr-Gama, G. P. S. Julião, I. Proscurshim, A. S. Neto, and J. Gama-Rodrigues, "Transanal endoscopic microsurgery for residual rectal cancer after neoadjuvant chemoradiation therapy is associated with significant immediate pain and hospital readmission rates," Diseases of the Colon and Rectum, vol. 54, no. 5, pp. 545-551, 2011.

[145] G. M. J. Bokkerink, E. J. R. de Graaf, C. J. A. Punt et al., "The CARTS study: chemoradiation therapy for rectal cancer in the distal rectum followed by organ-sparing transanal endoscopic microsurgery," BMC Surgery, vol. 11, article 34, 2011.

[146] A. Dzik-Jurasz, C. Domenig, M. George et al., "Diffusion MRI for prediction of response of rectal cancer to chemoradiation," The Lancet, vol. 360, no. 9329, pp. 307-308, 2002.

[147] A. F. DeVries, C. Kremser, P. A. Hein et al., "Tumor microcirculation and diffusion predict therapy outcome for primary rectal carcinoma," International Journal of Radiation Oncology Biology Physics, vol. 56, no. 4, pp. 958-965, 2003.

[148] P. A. Hein, C. Kremser, W. Judmaier et al., "Diffusionweighted magnetic resonance imaging for monitoring diffusion changes in rectal carcinoma during combined, preoperative chemoradiation: preliminary results of a prospective study," European Journal of Radiology, vol. 45, no. 3, pp. 214222, 2003.

[149] L. Curvo-Semedo, D. M. J. Lambregts, M. Maas et al., "Rectal cancer: assessment of complete response to preoperative combined radiation therapy with chemotherapyconventional MR volumetry versus diffusion-weighted MR imaging," Radiology, vol. 260, no. 3, pp. 734-743, 2011.

[150] S. H. Kim, J. Y. Lee, J. M. Lee, J. K. Han, and B. I. Choi, "Apparent diffusion coefficient for evaluating tumour response to neoadjuvant chemoradiation therapy for locally advanced rectal cancer," European Radiology, vol. 21, no. 5, pp. 987-995, 2011. 
[151] Y. S. Sun, X. P. Zhang, L. Tang et al., "Locally advanced rectal carcinoma treated with preoperative chemotherapy and radiation therapy: preliminary analysis of diffusion-weighted MR imaging for early detection of tumor histopathologic downstaging," Radiology, vol. 254, no. 1, pp. 170-178, 2010.

[152] B. M. Ghadimi, M. Grade, M. J. Difilippantonio et al., "Effectiveness of gene expression profiling for response prediction of rectal adenocarcinomas to preoperative chemoradiotherapy," Journal of Clinical Oncology, vol. 23, no. 9, pp. 18261838, 2005.

[153] K. H. Brettingham-Moore, C. P. Duong, D. M. Greenawalt et al., "Pretreatment transcriptional profiling for predicting response to neoadjuvant chemoradiotherapy in rectal adenocarcinoma," Clinical Cancer Research, vol. 17, no. 9, pp. 30393047, 2011.

[154] E. Balboa, G. Duran, M. J. Lamas et al., "Pharmacogenetic analysis in neoadjuvant chemoradiation for rectal cancer: high incidence of somatic mutations and their relation with response," Pharmacogenomics, vol. 11, no. 6, pp. 747-761, 2010.

[155] S. Brophy, K. M. Sheehan, D. A. McNamara, J. Deasy, D. J. Bouchier-Hayes, and E. W. Kay, "GLUT-1 expression and response to chemoradiotherapy in rectal cancer," International Journal of Cancer, vol. 125, no. 12, pp. 2778-2782, 2009.

[156] E. Casado, V. M. García, J. J. Sánchez et al., "A combined strategy of SAGE and quantitative PCR provides a 13gene signature that predicts preoperative chemoradiotherapy response and outcome in rectal cancer," Clinical Cancer Research, vol. 17, no. 12, pp. 4145-4154, 2011.

[157] U. Drebber, M. Lay, I. Wedemeyer et al., "Altered levels of the onco-microRNA 21 and the tumor-supressor microRNAs 143 and 145 in advanced rectal cancer indicate successful neoadjuvant chemoradiotherapy," International Journal of Oncology, vol. 39, no. 2, pp. 409-415, 2011.

[158] J. Garcia-Aguilar, Z. Chen, D. D. Smith et al., "Identification of a biomarker profile associated with resistance to neoadjuvant chemoradiation therapy in rectal cancer," Annals of Surgery, vol. 254, no. 3, pp. 486-492, 2011.

[159] A. Ho-Pun-Cheung, E. Assenat, C. Bascoul-Mollevi et al., "A large-scale candidate gene approach identifies SNPs in SOD2 and IL13 as predictive markers of response to preoperative chemoradiation in rectal cancer," Pharmacogenomics Journal, vol. 11, no. 6, pp. 437-443, 2011.

[160] Y. Toiyama, Y. Inoue, S. Saigusa et al., "Gene expression profiles of epidermal growth factor receptor, vascular endothelial growth factor and hypoxia-inducible factor-1 with special reference to local responsiveness to neoadjuvant chemoradiotherapy and disease recurrence after rectal cancer surgery," Clinical Oncology, vol. 22, no. 4, pp. 272-280, 2010. 


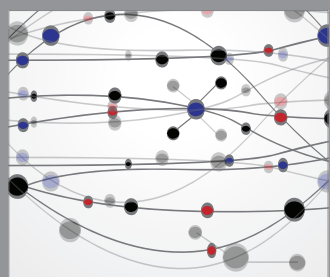

The Scientific World Journal
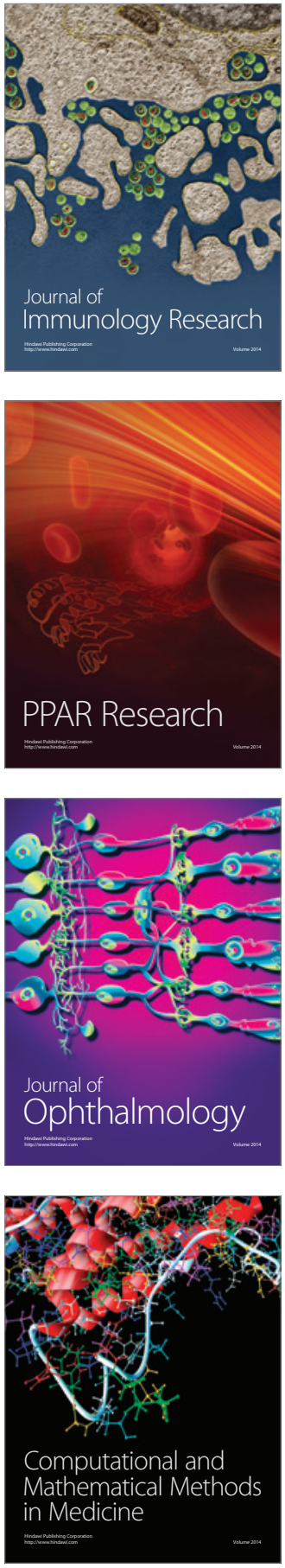

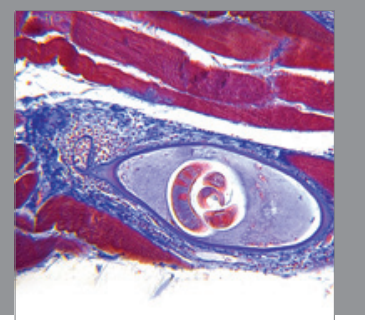

Gastroenterology

Research and Practice
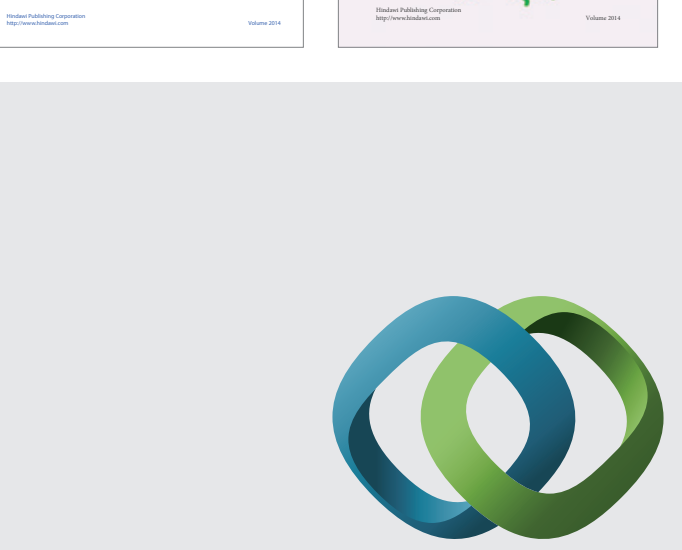

\section{Hindawi}

Submit your manuscripts at

http://www.hindawi.com
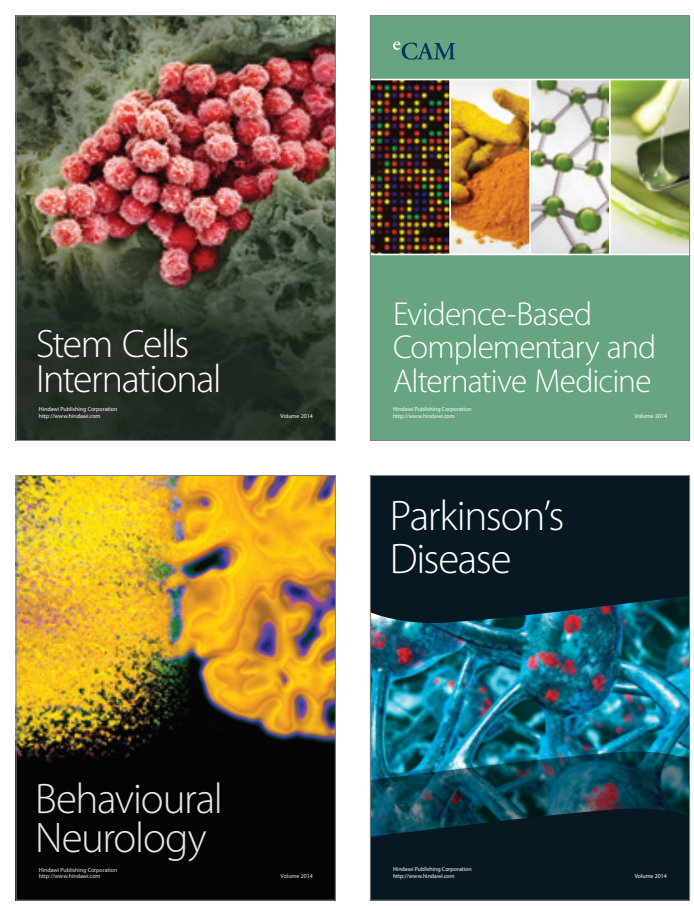

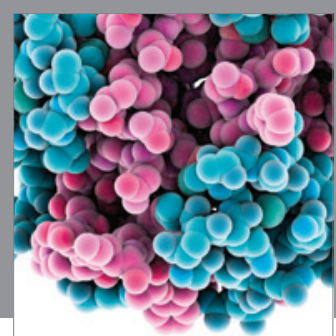

Journal of
Diabetes Research

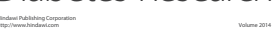

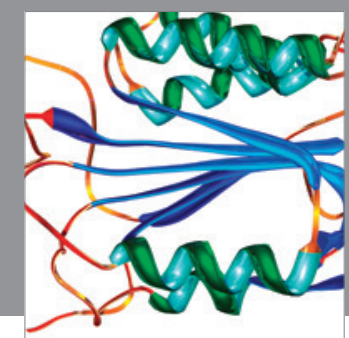

Disease Markers
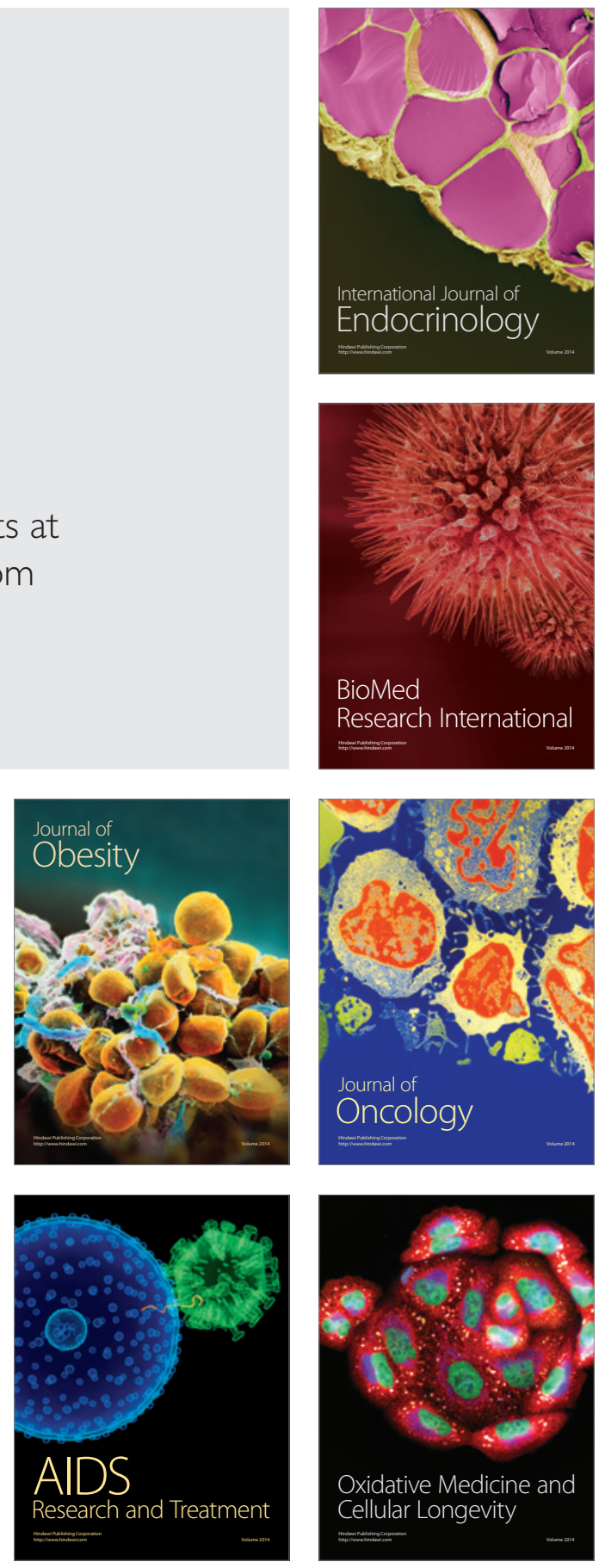